\title{
Culture conflict amongst Malaysian children
}

\begin{abstract}
Culture is an essential part of conflict and conflict resolution. Culture is in our lives and relationships, giving us messages that shape our perceptions, attributions, judgments, and ideas of self and others. Though cultures are powerful, they are often unconscious, influencing conflict and attempts to resolve conflict in imperceptible ways. Two things that are essential to remember about culture: they are always changing, and they relate to the symbolic dimension of life. The symbolic dimension is the place where we are constantly making meaning and enacting our identities. Cultural messages from the groups we belong in giving us information about what is meaningful or important, and who we are in the world and in relation to others. Therefore, this paper will discuss the culture conflict undergo by children in Malaysia arise from different cultural groups i.e ethnicity, from generation, socioeconomic class, sexual orientation, ability and disability, and religious affiliation, language, and gender. The study sample comprises from 30 primary school students from three locations; urban, city and rural areas in Malaysia. Data were gathered using recording, interview, and questionnaire. Data will be analysed by using socio-pragmatic approach. The outcome of the research also indicated that aspects of context and cognition have also played an important role to overcome the cultural conflicts among Malaysian children.
\end{abstract}

Keyword: Malaysian culture, conflict, primary school students 